\title{
The Internal Side of the Person-Centered Approach and Meditative Practice
}

\section{Gérard Mercier*}

Person-Centered Approach French Association of Psychotherapy, France

As the Chinese energy arts have an outer dimension (Kung Fu, wing shu, Wushu) and an internal component (Tai Chi Chuan, Gi Gong), the Centered Approach to Person (ACP) presents itself as a similar expression.

Its external aspect is within the relational quality that the therapist offers the client, living fabric whose fibers network over by a dynamic tension that chairs the six conditions set by Rogers including 3 nodal attitudes, own therapist, play a decisive role.

For the therapeutic process to occur, it must have:

- Two persons are in psychological contact.

- The first person, whom we will call the client, is in a state of internal disagreement, vulnerability or anxiety.

- The second person, whom we call the therapist, is in a state of internal agreement at least for the duration of the interview and in relation to the object of his relationship with the client.

- The therapist experiences feelings of unconditional positive regard towards the subject.

- The therapist experiences an empathic understanding of the client's internal frame of reference.

- The customer perceives - if only as a measure in the presence of minimal - 4 and 5, i.e., unconditional positive regard and empathic understanding that the therapist showed him [1]

The internal dimension of the CPA meets in two complementary areas: work on oneself therapist during personal therapy, and during his experiential training, both initial and continuing (supervision).

I will not pretend here that meditative practice can only be reduced to this internal aspect converged with attitudes that the therapist offers him even. Elle refers above all to what John Welwood calls "a psychology of enlightenment" that recognizes "the broader area of consciousness stripped of ego" [2]. Domain on which I will not venture here, with regard to the proper spiritual aspect of meditation.

Nevertheless, the experience here and there led me to understand that the internal facet of the ACP would be similar to self-experience as practitioners of meditation describe. This would be an internalization of three fundamental attitudes taken to yourself. In other words, practice meditative describe how the person offers itself congruence, unconditional positive regard and empathic understanding

\section{Congruence and Meditative Practice}

Barbara Termaner Brodley explains the congruence as "the capacity and activity of exactly symbolized experiments in consciousness" and again "People are congruent if in awareness, their symbols are appropriate to the perceptions she experience it" [3].

Rogers "The psychological adjustment exists when the concept of the ego is such that all the sensory and visceral experiences of the organization are, or may be assimilated in symbolic form a relationship with the concept of the self"[4].

Congruence, in its most intimate to the heart of self- relationship to itself, opens a phenomenological field of perceptions, sensations and feelings that make up the partition of the internal movement of being.

Fabrice Midal is probably one of Francophone practitioners who strives to testify closer to the meditative experience says that "The meditative practice, he writes, does not to deny the thoughts that arise, to seek to enter a static state without thought, but to recognize them, then return to the present. Meditation is not intended to teach us to rid ourselves of our emotions but to show them more attention. It is not, nor accepts an emotion or reject but to fully know her". This sentence, that Rogers would probably not challenged, is the expression of congruence in that it has more internal, where we meet ourselves in personal therapy [5].

Further the author writes "The practice is precisely to have the lucidity and courage to confront us with what we are, as we are and to open ourselves to the difficulties ahead" [5]

\section{Acceptance and Unconditional Two - Meditative Practice}

On the relational side, writes Brian Thorne "the acceptance or rather the unconditional positive regard involves the therapist a blank care of any value judgment on the thoughts, feelings or customer behavior [6]. There can be no question that the therapist accepts some aspects of his client and rejects others; that acceptance extends to the full range of feelings and attitudes, hostility and indifference to the love and joy". How to design the therapist can offer this level of hospitality it to his client and, with him, refusing intimate configurations that should put under quarantine, see hitting disapproving anathema these, at the hands of a narrow morality, do not they will crystallize punitive autoculpabilisation?

What I saw in therapy falls under the path of acceptance. "This is not based on hatred, but on tenderness, one that is not aggression but trust? Very strikingly accept our imperfections, accept to be more vulnerable than we like it or not, releases a suffocating weight. We do not have to defend ourselves all the time about everything" [5].

\section{Empathic Understanding and Practice of Meditation}

According to Brian Thorne "The therapist must understand how the customer is himself and sees the world [6]. This implies understanding the therapist's desire and ability to penetrate fearlessly into the world of personal perceptions of his client and become familiar" [6].The meditative experience opens for oneself comprehension spaces that

*Corresponding author: Gérard Mercier, Doctor of Psychology, Psychotherapis authorized AFP-ACP, France, Tel: 03815269 39; E-mail: gerardmercier25@yahoo.fr

Received January 27, 2016; Accepted January 28, 2016; Published February 04, 2016

Citation: Mercier G (2016) The Internal Side of the Person-Centered Approach and Meditative Practice. J Psychol Abnorm S1: e002. doi:10.4172/jpab.S1-e002

Copyright: ( 2016 Mercier G. This is an open-access article distributed under the terms of the Creative Commons Attribution License, which permits unrestricted use, distribution, and reproduction in any medium, provided the original author and source are credited. 
reveal the inner aspect of empathy and "means to open ourselves to our experience, to cope and to work as we are, to Instead of trying aggressively to transform us into something different" [2].

Empathy per opens an affirmation of life contained way, sometimes thorny padlocked in the structures of the self, "Whatever be the thing with which we struggle, whatever the thing that seems most neurotic, she can be an important stepping stone on our way. Whatever the problem, issue or confusion we have, regardless of what seems impossible to us in our lives, if we go to this, if we see it, feel it, establish a relationship with and use, this becomes our way" [2]

Being friends with the form, include a fund that seeks to manifest itself otherwise than by suffering or disorder that affects me", it also means that you communicate what you perceive of this world, YMMV $\mathrm{d}$ a new eye and without fear of things which the individual is afraid" [6]. Here in the meditative experience, this individual is myself.

"The client-centered therapy, as Centered Approach the person in its various applications, based on a theory of attitudes". Barbara Termaner Brodley writes that its outer side of nature and interpersonal relationships. Its internal art concerns the meditative practice: congruence, unconditional positive acceptance and empathic understanding toward oneself are the heart of the movement of life as I am in personal therapy and supervision [3]. The student writes Barbara Termaner Brodley's experiences the application of therapeutic attitudes and observe the effects of both the inside and outside. "This double movement leading dialectic between the implementation of movement attitudes internally and the therapeutic component coming promote climate facilitating offered to the customer" [3]. In this process of therapeutic development staff, maintain congruence and experience attitudes of unconditional positive regard and empathic understanding becomes important qualities in building the personality of the therapist in the relationship with customers at least" [3]. In itself, as in meditation practice, there is in putting into perspective the three attitudes in line triple form of transcendence: "Living totally his body, working with his psychological patterns, taking his true form, $\mathrm{c}$ is the work that is to connect with the earth, the terrestrial principle in action" [2] is this not the expression of congruence? And the author to continue "As long as we stay stuck in a limited understanding of qi we are, these kleshas (the word denotes klesha in Buddhist practice the five trends or causes of suffering: the attachment, aggression, ignorance, jealousy and pride) continue to rise, regardless of the amount of psychotherapy we have followed [2]. When we no longer have to reject our neurotic tendencies, we have more compassion and vis-à-vis understanding of how they also affect others [2]? This work on the soul Buddhist heavenly principle, would be one of the forms taken by the unconditional positive regard for ourselves.
Finally "the interaction of the earth and sky, to take shape and let go vis-a -vis this form gives birth to third inner working principle -l'eveil the heart, which is in Chinese thinking principle of man ( the human ). Awakening involves the heart out of our character armor to accommodate the reality in us and other beings [2]. Is it not also the expression of empathic understanding for oneself.

In summary, the center of the meditative process:

- Connect to the earth and take shape - the principle terrestrecorresponds to the internal manifestation of congruence;

- The heavenly principle, the unconditional positive acceptance;

- The human principle has empathic understanding per se.

Three levels are in dialogue and additional support here, within a phenomenology of meditative practice. However, warns Fabrice Midal, "Meditation is not a treatment, it is both less and more than that" [5]. Meditation moves the three attitudes on the intimate side of our presence to ourselves. The reception of our feelings, our fantasies and our sensations experienced in a climate of understanding can draw a path of awakening.

Work on yourself and join relational quality in a double helix efficiency and recollection whose resultant is the presence evidenced by Rogers [6] "I discovered that when I'm really close to my inner self, intuitive, if somehow I am in contact with the unknown in me, maybe when I'm in a slightly different state of consciousness (altered) during the relationship, I think, whatever I do, what I do is deeply therapeutic. My mere presence is effective and beneficial. I cannot do anything to cause this condition, but when I am relaxed while being myself close to my transcendental core, sometimes I have strange and impulsive behavior [6]. But very strangely, this curious behavior proves appropriate. At these times I feel that my spirit reaches the mind of another. Our relationship transcends itself and becomes a part of something bigger. I then found the presence of an in-depth progress of growth, a cure, a great energy". As a back-and-forth from meditation to communion.

\section{References}

1. Rogers CR (2009) Psychotherapy and human relationships. Theory Therapy Focused on the person. ESF Editors.

2. WelWood J (2003) For a psychology of enlightenment. The Round Table 67

3. Brodley BT (2013) The congruence and its relation to client-centered therapy in communication. ACP Practice and Research 17: 28-64.

4. Heneman $\mathrm{H}$ (1951) A theory of personality and behavior. carl-rogers 15: 24 .

5. Midal F (2012) Meditation Practice. The paperback 31-34.

6. Thorne B (1994) Understanding Carl Rogers (third edition) SAGE Publications Ltd 56. 